\title{
Sustainability and Maintainability of High Rise Vertical Greenery Systems (VGS): its Lessons and Assessment Scoresheet
}

\author{
Sheila Conejos ${ }^{1}$ and Michael Y.L. Chew $^{2}$ \\ ${ }^{1}$ School of Science and Technology, Singapore University of Social Sciences, \\ sheilaconejos@suss.edu.sg \\ ${ }^{2}$ Department of Building, National University of Singapore
}

\begin{abstract}
Vertical Greenery Systems (VGS) applied on building has proven economic, environmental and social benefits which made it one of the widely accepted green building design strategies to support sustainable development. However, incorporating vertical greenery systems into innovative facades generates maintainability challenges. This paper highlights the best and good practices Design for Maintainability scoresheet, as well as the VGS defects and issues. The Design for Maintainability (DfM) assessment scoresheet will be beneficial in assessing and avoiding potential VGS defects leading to its maximum performance, longevity and sustainability. This research has established a list of best practice guidelines and measures with weighted scoring system for evaluating the maximum performance and efficient maintainability of VGS applications on facades while minimizing cost, risks, negative environmental impacts and consumption of matter/energy. The paper's contribution will be the improvement of the designers' decision making process, expanded library on vertical greenery systems defects as well as the importance of integrating maintainability of high-rise VGS facades in tropical conditions during its design inception.
\end{abstract}

Keywords: Building Maintainability, Green Building Technologies, Multi-Criteria Decision Assessment, Vertical Greenery Systems (VGS), Singapore.

\section{Introduction}

Vertical Greenery Systems (VGS) applied on building has proven economic, environmental and social benefits (Chew and Conejos, 2016; Perini et al., 2017) which made it one of the widely accepted green building design strategies to support sustainable development. However, incorporating vertical greenery systems into innovative facades generates maintainability challenges such as spoilt or falling leaves (Wong et al., 2010), defective irrigation systems and inadequate installation methods which surges costs on operations and maintenance (Safikhani et al., 2014), damaged surfaces due to plant roots infiltrating cracks (Manso and Castro-Gomes, 2015), lack/insufficient maintenance access (Behm and Poh, 2012; Köhler, 2008; Perini and Rosasco, 2013; Pérez et al., 2014).

Chew and Conejos (2016) reports that less research has been undertaken concerning the maintainability of VGSs in tropical settings via design-based values, since this entails the vertical greenery system's sustainability (Emilsson, et al., 2007). There is a need for the development of guidelines for VGS sustainability (Dvorak and Volder, 2010; Giordano et al., 2017) which prompted the development of the Design for Maintainability guidelines for high rise vertical greenery systems in the tropics by Chew et al. (2019).

Chew and Conejos (2016) highlights various vertical greenery systems defects and issues in 
Singapore and categorize them into technical and environmental defects based on previous research study and continually establishes more evidenced based issues and defects through qualitative approaches in this study in order to ascertain best practices as basis for a Design for Maintainability scoresheet in support for the design decision tool developed to assess the performance of vertical greenery systems.

\section{Green Maintainability}

The Green Maintainability concept (Chew, 2016; Conejos et al., 2019) was established with the five green maintainability factors which incorporated facility management with sustainability right at the outset; such as: (1) maximizing performance - refers to the optimal competence of the building's function through design values, building science and engineering, efficient energy use and sustainability; (2) minimizing cost - pertains to the decrease in operations and maintenance costs and boosting savings throughout the entire building lifespan;

(3) minimizing risk - denotes to the reduction of possible building defects occurrences and risks in the future; (4) minimizing negative environmental impact - concerns in the decrease of potential damaging effects caused by the discharge of a substance in the environment; and (5) minimizing consumption of matter and energy - indicates the conservation and management of the building's material, water and energy usage.

\section{Research Methods}

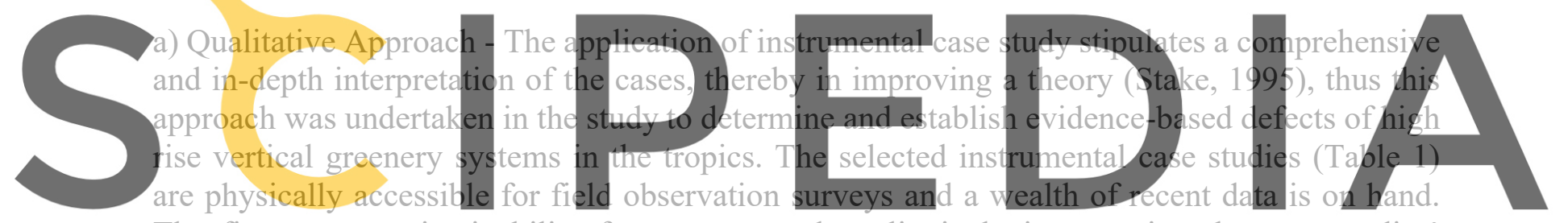

The five green maintainability factors are used qualitatively in assessing the case studies'

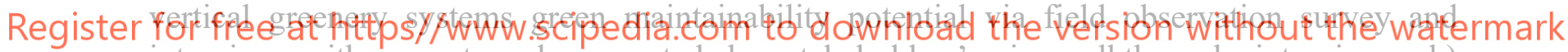
interview with expert and supported by stakeholders' via walkthrough interviews. b) Quantitative Approach - To provide an assessment scoresheet, a survey was conducted among practitioners and experts involved in designing and installing green facades. The Analytical Hierarchy Process (AHP) which is proven robust (Saaty, 1980) was used in analyzing the coded survey data in excel format. 
Table 1. Instrumental Case Studies.

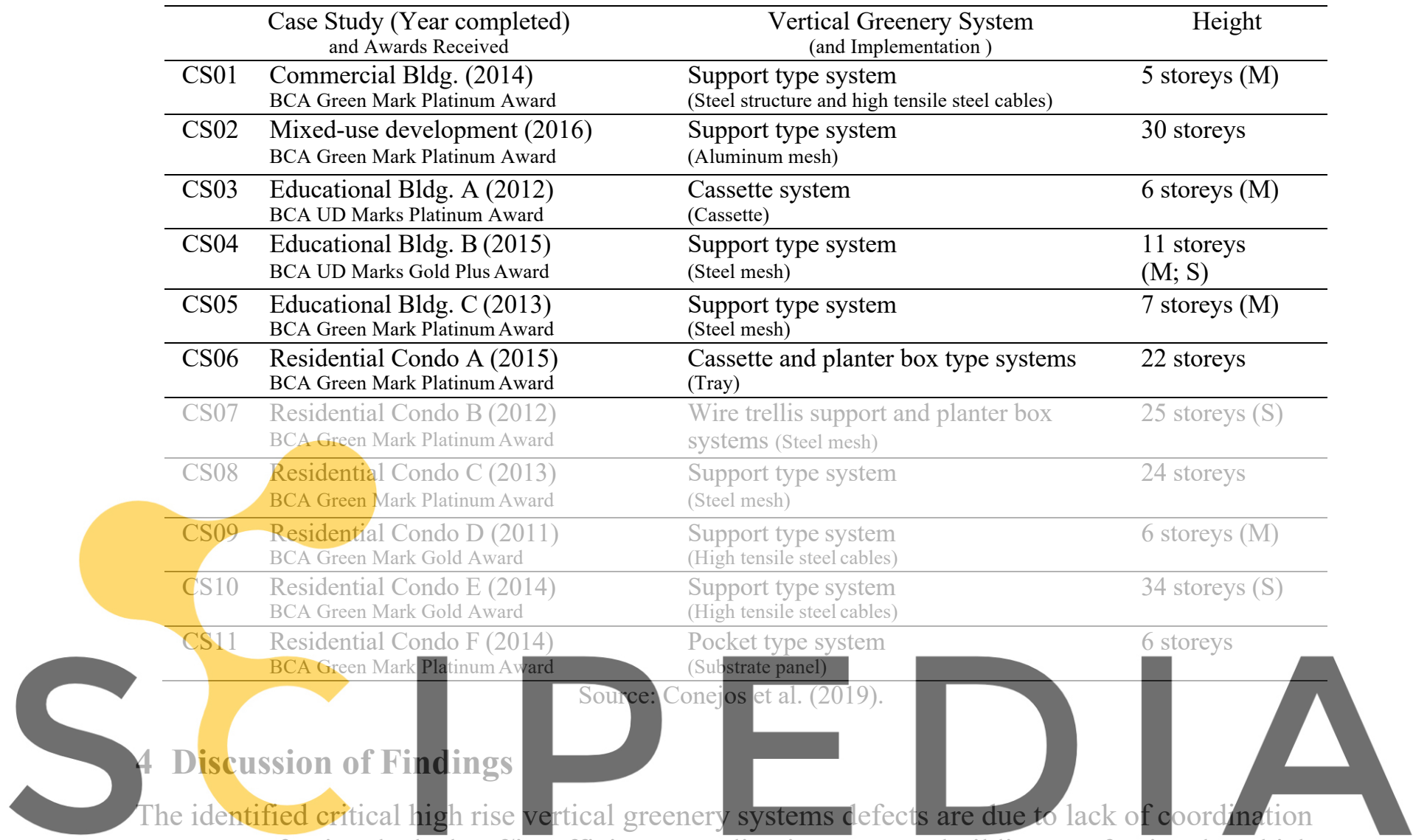

among professionals lack of/insufficient coordination among building professionals which

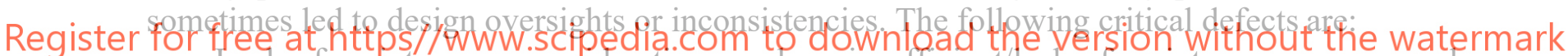
Lack of maintenance considerations such as insufficient/lack of maintenance access and safety issues/risks during cleaning and repairs. In some case studies, workers have to get through private balconies, pump rooms and air-conditioning units; climb over pool, parapet or glass enclosure; pass through pillars and traverse into narrow corridors that inhibits bulky maintenance equipment.

- VGS installation at the pool deck or over it which required frequent cleaning to preserve water quality.

- Lack/improper drainage system due to flat gradient or no screeding or lacking drains which causes water stagnation/ponding that will lead to pest infestation, mosquito breeding and algae/mould growth. In some instances, the drainage gutter has chokage issues due to falling leaves leading to water stagnation and possible mosquito breeding that will affect the health of residents and the public.

- Issues concerning infrequent/improper maintenance regimes due to the evident fallen leaves and dirt accumulation caused by heavy rainfall and strong winds. In some cases, the vines on the steel cable have thickened putting additional load to the support as it was not pruned or well maintained.

- Withering plants due to the suitability of plant species where in some cases where non- 
tropical plants were installed which led to the drying and dying of plant species. The wrong choice of plant species can be considered a design oversight.

- Poor/faulty irrigation and water dripping issues caused by chokage or faulty components will lead to irregular plant growth or plants dying, rust of structural components, and high water consumption costs.

- Insufficient sunlight exposure also prevents plant growth and lead to plant dying or premature plant replacement regardless of proper irrigation regimes.

- Issues on maintenance cost (i.e. LCC) which entails a high cost of expenses when maintaining defective VGS.

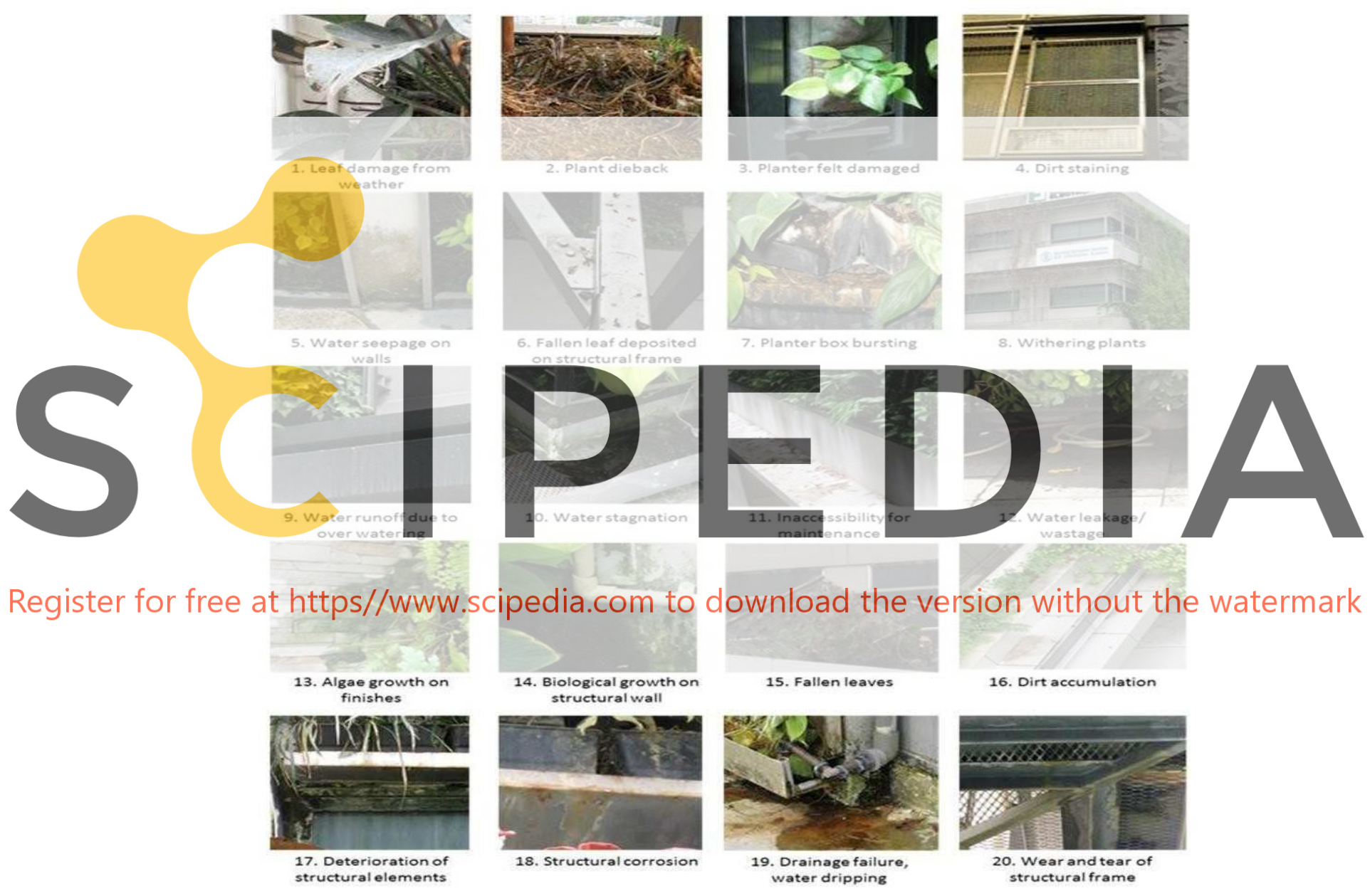

Figure 1. Some Defects of Vertical Greenery Systems.

(Source: Chew and Conejos, 2016).

\section{Design for Maintainability (DfM) Scoresheet}

In previous research studies, the Design for Maintainability (DfM) guidelines (Chew et al. 2019) and checklist (Conejos, et al. 2019) for vertical greenery systems has been established. In this study, the checklist is further developed into a graded scoring system which will assess 
the vertical greenery systems' total performance according to the five green maintainability factors. The DfM scoresheet for high rise vertical greenery systems, highlights fourteen (14) design criteria with corresponding DfM good practice measures/guidelines and corresponding percentage scores with a total score of $100 \%$ when summed up (Table 2). The design criteria are grouped under the five green maintainability factors with corresponding percentages that totaled to $100 \%$ such as (1) maximizing performance $-21.47 \%$; (2) minimizing cost $-17.45 \%$; (3) minimizing risk $-30.81 \%$; (4) minimizing negative environmental impact $-13.85 \%$; and (5) minimizing consumption of matter and energy $-16.42 \%$. Each design criterion is equally distributed according to the scoring percentage of each green maintainability factor. Based on the practitioner and expert survey results, the most critical green maintainability factor to be considered is minimizing risk which pertains to safety measures including fire safety and quality workmanship.

The importance of considering the green maintainability of a building throughout its life cycle will improve the sustainability and performance of high-rise vertical greenery systems in the tropics. The proposed checklist may aid in addressing the maximum performance and efficient maintainability of VGS applications on facades while minimizing cost, risks, negative environmental impacts and consumption of matter/energy.

\section{Conclusions}

This research has shown that considering maintainability right at the design inception is of great

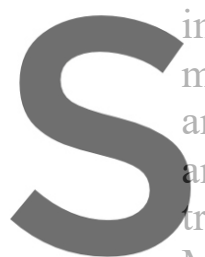
importance. Designing maintain guarantees lo and issues of vertical gre nd good practices has introduced a set of ranslated into a weighted scoresheet for ass
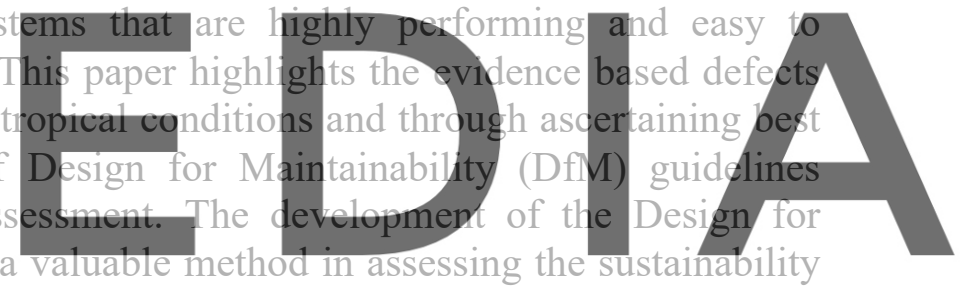

and maintainability potential of high-rise vertical greenery systems. The best practices and

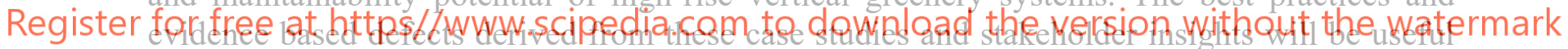

in improving the decision making process for designers when it comes to the choice and design

of VGS, as well as the expansion of the vertical greenery defects library. Lastiy, one of the most important goals of VGS implementation is to promote a biophilic environment within high density areas as well as support climate change adaptation through the greening of the built environment.

\section{ORCID}

Sheila Conejos: https://orcid.org/0000-0001-6430-7042

Michael Y.L. Chew: https://orcid.org/0000-0002-3190-4315

\section{References}

Behm, M. and Poh, C.H. (2012). Safe design of skyrise greenery in Singapore, Smart and Sustainable Built Environment, 1 (2), 186-205. doi:10.1108/20466091211260677.

Chew, M.Y.L. (2016). Maintainability of facilities: Green FM for building professionals (2nd ed.), Singapore: World Scientific.

Chew, M.Y.L. and Conejos, S. (2016). Developing a green maintainability framework for green walls in 
Singapore, Structural Survey, 34(4/5), 379-406. doi:10.1108/SS-02-2016-0007.

Chew, M.Y.L., Conejos, S. and Azril, F.H.B. (2019). Design for maintainability of high-rise vertical green facades, Building Research \& Information, 47 (4), 453-467. doi: 10.1080/09613218.2018.1440716.

Conejos, S., Chew, M.Y.L. and Azril, F.H.B. (2019). Green maintainability assessment of high-rise vertical greenery systems, Facilities, 37 (13/14), 1008-1047. doi: 10.1108/F-09-2018-0107.

Dvorak, B. and Volder, A. (2010). Green roof vegetation for North American ecoregions: A literature review, Landscape and Urban Planning, 96(4), 197-213. doi:10.1016/j.landurbplan. 2010. 04. 009.

Emilsson, T., Berndtsson, J., Mattssona, J. and Rolfa, K. (2007). Effect of using conventional and controlled release fertilizer on nutrient runoff from various vegetated roof system, Ecological Engineering, 29(4), 260271. doi:10.1016/j.ecoleng.2006.01.001.

Giordano, R., Montacchini, E., Tedesco, S. and Perone, A. (2017). Living wall systems: A technical standard proposal, Energy Procedia, 111, 298-307. doi:10.1016/j.egypro.2017.03.093.

Köhler, M. (2008). Green facades - a view back and some visions, Urban Ecosystems, 11(4), $423-436$. doi:10.1007/s1 1252-008-0063-x.

Manso, M. and Castro-Gomes, J. (2015). Green wall systems: A review of their characteristics, Renewable and Sustainable Energy Reviews, 41, 863-871. doi:10.1016/j.rser.2014.07.203.

Pérez, G., Coma, J., Martorel1, I. and Cabeza, L. F. (2014). Vertical greenery systems (VGS) for energy saving in buildings: A review, Renewable and Sustainable Energy Reviews, 39, 139-165. doi:10.1016/j.rser.2014.07.055

Perini, K. and Rosasco, P. (2013). Cost-benefit analysis for green façades and living wall systems, Building and Environment, 70, 110-121. doi:10.1016/j.buildenv.2013.08.012.

Perini, K., Magliocco, A. and Giulini, S. (2017).Vertical greening systems evaporation measurements: Does plant species influence cooling performances? International Journal of Ventilation, 16(2), 152-160. doi:10.1080/14733315.2016.1214388

Saaty, T. L. (1980). The analytic hierarchy process, McGraw-Hill Inc., New York, US.

Safikhani, T., Abdullah, A. M., Ossen, D. R. and Baharvand, M. (2014). A review of energy characteristic of

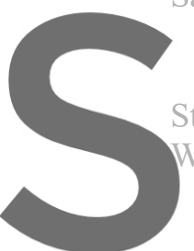
vertical greenery do1:10.1016/j.rser.2014.07.166

Stake, R.E. (1995). The Art of

ong, N. H., Tan, A. Y. K.

systems in Singapd doi:10.1061/(ASCE)UP
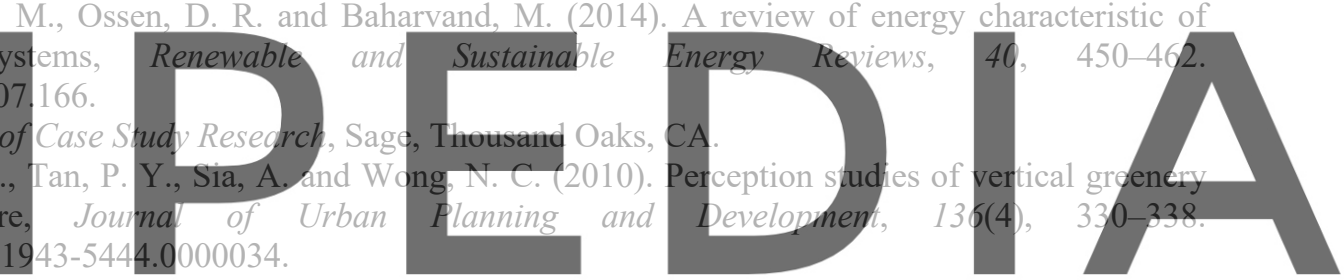

Register for free at https//www.scipedia.com to download the version without the watermark 


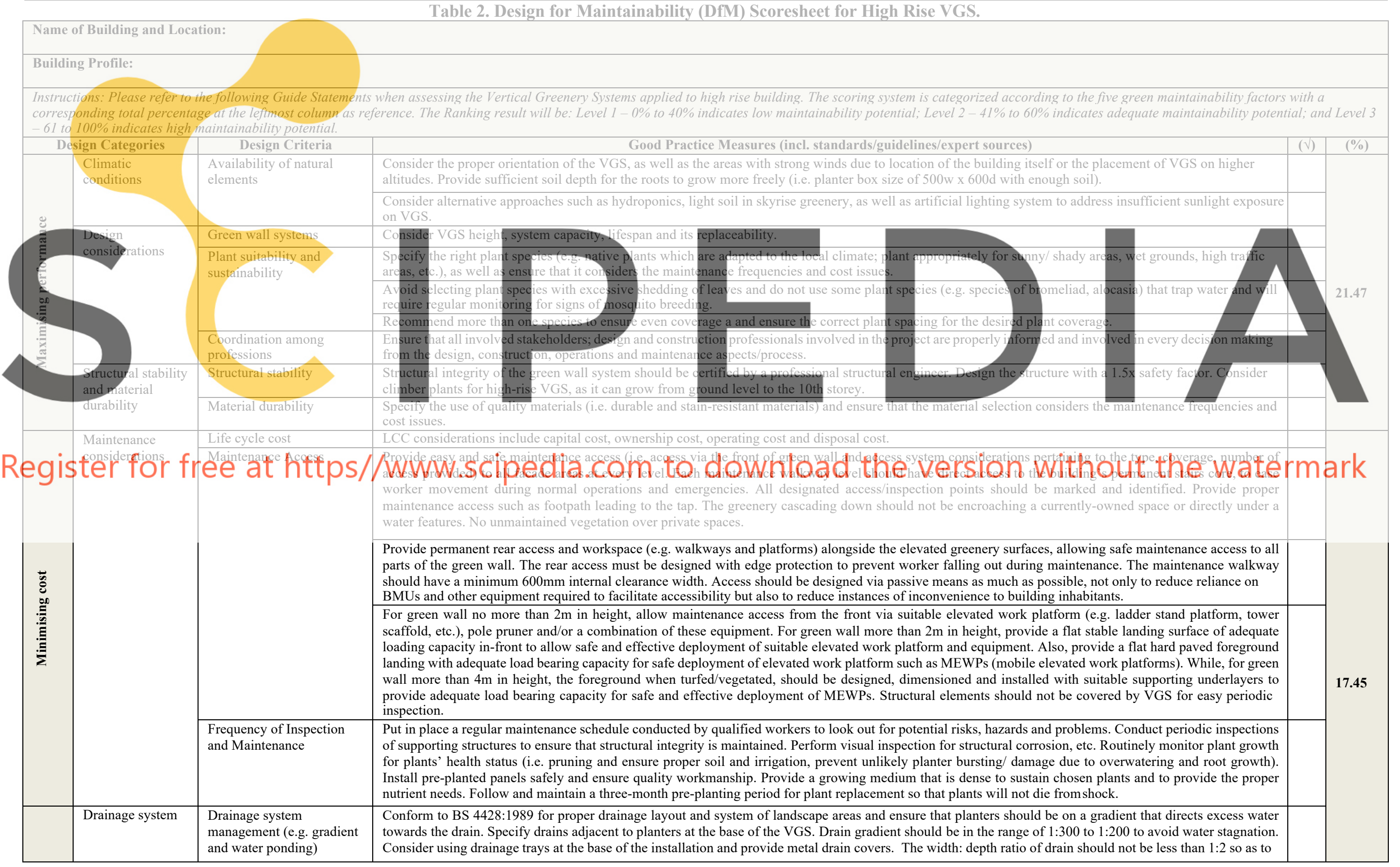




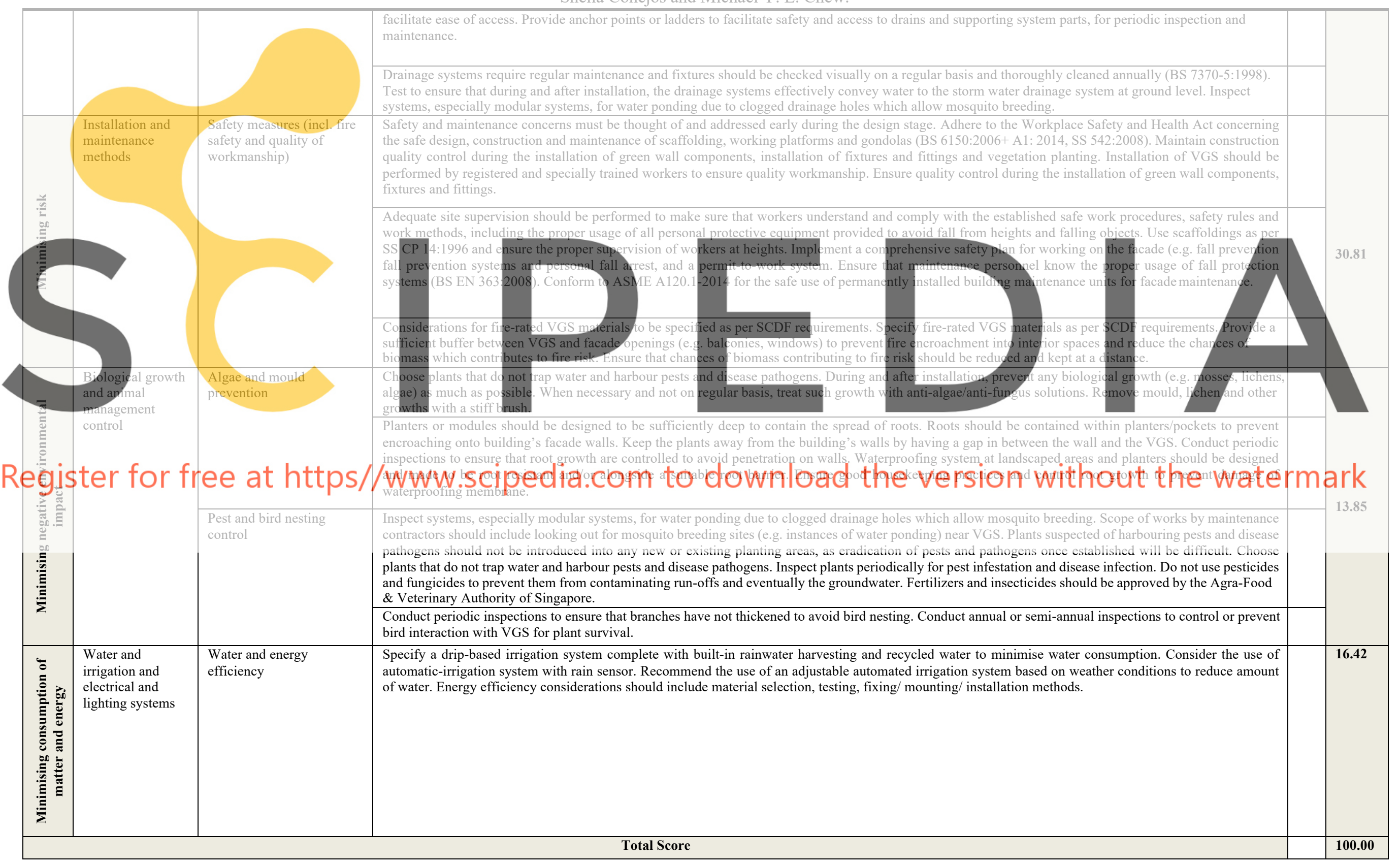

